\title{
DERMATOMICOSE EM CÃO CAUSADA POR Curvularia sp.: RELATO DE CASO
}

\author{
Darilha Mariana Rodrigues ${ }^{1}$ \\ Rodrigo de Oliveira Mattosinho 2 \\ Bruna Letícia Domingues Molinari ${ }^{3}$ \\ Juliana Evangelista Bezerril ${ }^{4}$ \\ Paulo Fernandes Marcusso ${ }^{5}$ \\ Thalita Regina Petrillo 3
}

\begin{abstract}
RESUMO
As dermatomicoses são infecções fúngicas que afetam a pele e os folículos pilosos de cães e gatos, causadas principalmente por dermatófitos, sendo observado principalmente em animais jovens e imunossuprimidos. Caracterizada clinicamente pela presença de lesões alopécicas circulares, encobertas por escamas e crostas. Sua presença assídua na clínica de pequenos animais, não excluí sua complexidade para concluir diagnóstico, sendo necessário uma gama de exames complementares, assim como a cultura fúngica, exame direto e biópsia de pele, que fazem parte de exames complementares de extrema importância e eficácia, auxiliando no diagnóstico e tratamento das dermatomicoses. Os fungos do gênero Curvularia spp., são nãodermatófitos e podem ser encontrados com grande frequência em diferentes substratos vegetais, como saprofíticos, podendo ainda ser isolados a partir do solo e do ar, causando diversas doenças em animais, humanos e vegetais, sendo considerados patógenos oportunistas. A falta de informação sobre tal afecção cutânea, assim como a investigação na clínica médica e na rotina clínica de pequenos animais, mostra a importância de considerar esse patógeno nos casos de dermatomicoses. O presente trabalho relata dermatomicose em cão causada por Curvularia spp. tendo como objetivo demonstrar as diferentes formas de diagnóstico para tal enfermidade, a fim de instituir terapêutica medicamentosa visando resultados benéficos e prognóstico favorável.
\end{abstract}

Palavras Chave: dermatopatia, canino, fungos, diagnóstico, tratamento.

\section{DERMATOMYCOSIS IN DOG CAUSED BY Curvularia sp.: CASE REPORT}

\begin{abstract}
Dermatomycoses are fungal infections that affect the skin and hair follicles of dogs and cats, caused mainly by dermatophytes, being observed mainly in young and immunosuppressed animals. Clinically characterized by the presence of circular alopecic lesions, covered by scales and crusts. Its assiduous presence in the small animal clinic does not exclude its complexity to complete the diagnosis, requiring a range of complementary tests, as well as fungal culture, direct examination and skin biopsy, which are part of complementary tests of extreme importance and effectiveness, assisting in the diagnosis and treatment of dermatomycoses. Fungi of the genus Curvularia spp., are non-dermatophytes and can be

\footnotetext{
${ }^{1}$ Graduada em Medicina Veterinária pelo Centro Universitário Ingá - UNINGÁ, Maringá.

${ }^{2}$ Médico veterinário do Hospital Veterinário do Centro Universitário Ingá - UNINGÁ, Maringá. mattosinho_vet@hotmail.com

${ }^{3}$ Docentes do curso de Medicina Veterinária do Centro Universitário Ingá - UNINGÁ, Maringá. bruna_molinari@hotmail.com

${ }^{4}$ Docente do curso de Medicina do Centro universitário de mineiros - UNIFIME. julianaevb2@gmail.com

5 Docente do curso de Medicina Veterinária da Universidade Federal dos Vales do Jequitinhonha e Mucuri - UFVJM. Correspondência: paulomarcuso@gmail.com
} 
found with great frequency in different plant substrates, such as saprophytes, and can also be isolated from soil and air, causing several diseases in animals, humans and plants, being considered opportunistic pathogens. The lack of information about such a skin condition, as well as the investigation in the medical clinic and in the clinical routine of small animals, shows the importance of considering this pathogen in cases of dermatomycosis. The present work reports dermatomycosis in dogs caused by Curvularia spp. aiming to demonstrate the different forms of diagnosis for such a disease, in order to institute drug therapy aiming at beneficial results and favorable prognosis.

Keywords: dermatopathy, canine, fungi, diagnosis, treatment.

\section{DERMATOMICOSIS EN PERRO CAUSADA POR Curvularia sp.: REPORTE DE CASO}

\section{RESUMEN}

Las dermatomicosis son infecciones fúngicas que afectan la piel y los folículos pilosos de perros y gatos, causadas principalmente por dermatofitos, observándose principalmente en animales jóvenes e inmunosuprimidos. Clínicamente caracterizado por la presencia de lesiones alopécicas circulares, cubiertas por escamas y costras. Su asidua presencia en la clínica de pequeños animales no excluye su complejidad para completar el diagnóstico, requiriendo un abanico de pruebas complementarias, así como cultivo de hongos, examen directo y biopsia de piel, que forman parte de pruebas complementarias de extrema importancia y efectividad. ayudar en el diagnóstico y tratamiento de dermatomicosis. Los hongos del género Curvularia spp., Son no dermatofitos y se pueden encontrar con gran frecuencia en diferentes sustratos vegetales, como los saprófitos, y también pueden aislarse del suelo y del aire, provocando diversas enfermedades en animales, humanos y plantas, siendo considerados patógenos oportunistas. La falta de información sobre tal condición de la piel, así como la investigación en la clínica médica y en la rutina clínica de los animales pequeños, muestra la importancia de considerar este patógeno en casos de dermatomicosis. El presente trabajo reporta dermatomicosis en perros causada por Curvularia spp. con el objetivo de demostrar las diferentes formas de diagnóstico de dicha enfermedad, con el fin de instituir la terapia con medicamentos con el objetivo de obtener resultados beneficiosos y un pronóstico favorable.

Palabras clave: dermatopatía, canina, hongos, diagnóstico, tratamiento.

\section{INTRODUÇÃO}

Dentre as dermatopatias com alta incidência na rotina clínica de cães e gatos, destacamse as dermatomicoses, causadas principalmente por dermatófitos. Contudo, outros fungos não-dermatófitos podem estar associados à dermatomicoses, como Aspergillus spp., Penicillium spp., Curvularia spp., Candida spp., Rhyzopus spp. (1).

Apesar da sua distribuição cosmopolita, existem poucos relatos nacionais que descrevem a Curvularia spp. como causadora de dermatomicose, sendo um caso em cão (2), e outro em equino (3). A Curvularia spp., são leveduras negras, oligotróficas, ou seja, possuem capacidade de sobrevivência em locais com baixa disponibilidade de água e nutrientes, elevada acidez, temperaturas acima de $37^{\circ} \mathrm{C}$ (4). 
A transmissão ocorre por contato direto com pelo e caspas de animais infectados ou fômites. Animais portadores, sem lesões visíveis que, ainda conduzem o material infeccioso, também são fontes de infecção (5).

O presente trabalho teve como objetivo descrever um relato de caso de uma dermatomicose causada por Curvularia spp. em cão.

\section{RELATO DO CASO}

Foi atendido no Hospital Veterinário do Centro Universitário Ingá (UNINGÁ), um cão, sem raça definida (SRD), macho, com 8 anos de idade, $6 \mathrm{~kg}$ de peso, tendo como queixa principal, acentuada queda de pelos e alopecia disseminada há aproximadamente 3 anos. Durante a anamnese a tutora relatou prurido intenso, uso antibiótico à base de enrofloxacino sem melhora clínica e episódios de polidipsia. Animal com normoúria, normofagia e normoquesia. Alimentação à base de ração, arroz e presunto, e petiscos.

Protocolos vacinais e de desvermifugação em dia. Habitava apenas ambiente externo da casa, em contato com outro cão, sem sinais clínicos. O ambiente apresentava grama e piso.

Durante exame clínico e físico o animal não apresentou alterações nos parâmetros vitais (TC: 38, $3^{\circ} \mathrm{C}$; FC: $96 \mathrm{bpm}$; FR $40 \mathrm{rpm}$; normohidratado; mucosas normocoradas; TRC 2") e linfonodos submandibulares reativos. Observou-se prurido intenso, pelos opacos e quebradiços com generalizada rarefação acompanhada de seborreia seca (Figura 1A), lesões alopécicas circulares, com colarinho seborreico e área central enegrecida, pele com perda de elasticidade (Figura 1B).

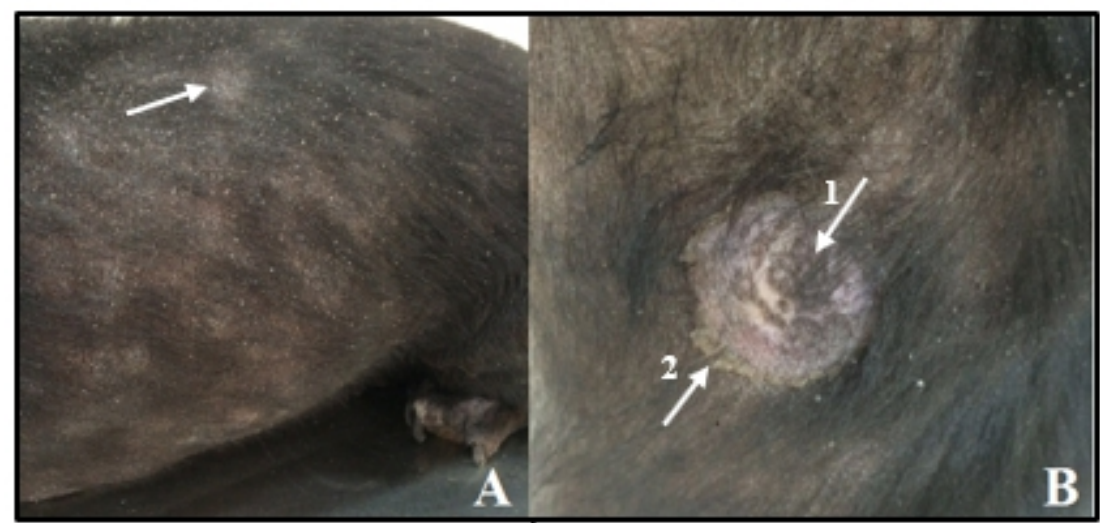

Figura 1. Setas demonstram: (A) Áreas alopécias circulares apresentando descamação intensa e seborréia disseminada. (B) Alopecia circular com região central enegrecida (seta 1), colarete epidermico (seta 2). Fonte: arquivo pessoal (2016).

Baseado nos sinais clínicos foram solicitados hemograma, bioquímica sérica de lesão hepática e função renal, raspado de pele, cultura fúngica e análise histopatológica.

Para realização dos exames hematológicos foram coletados $5 \mathrm{ml}$ de sangue por meio de punção da veia jugular, sendo $1,0 \mathrm{ml}$ acondicionado em tubo com EDTA para realização do hemograma e 4,0 $\mathrm{ml}$ em tubo seco para as análises bioquímicas séricas (creatinina, fosfatase alcalina - FA e alanina aminotransferase - ALT). O material foi imediatamente encaminhado para o Laboratório de Patologia Clínica do Hospital Veterinário da Uningá. Os resultados obtidos encontravam-se dentro dos valores de referência da espécie.

Foi realizado o raspado de pele nas extremidades das lesões circulares alopécicas e encaminhado ao Laboratório de Parasitologia Veterinária da Uningá, onde foram confeccionadas lâminas com clarificação em solução hidróxido de potássio - KOH (6), onde 
observou-se a presença de hifas e conídios com características compatíveis com Curvularia spp. (Figura 2).

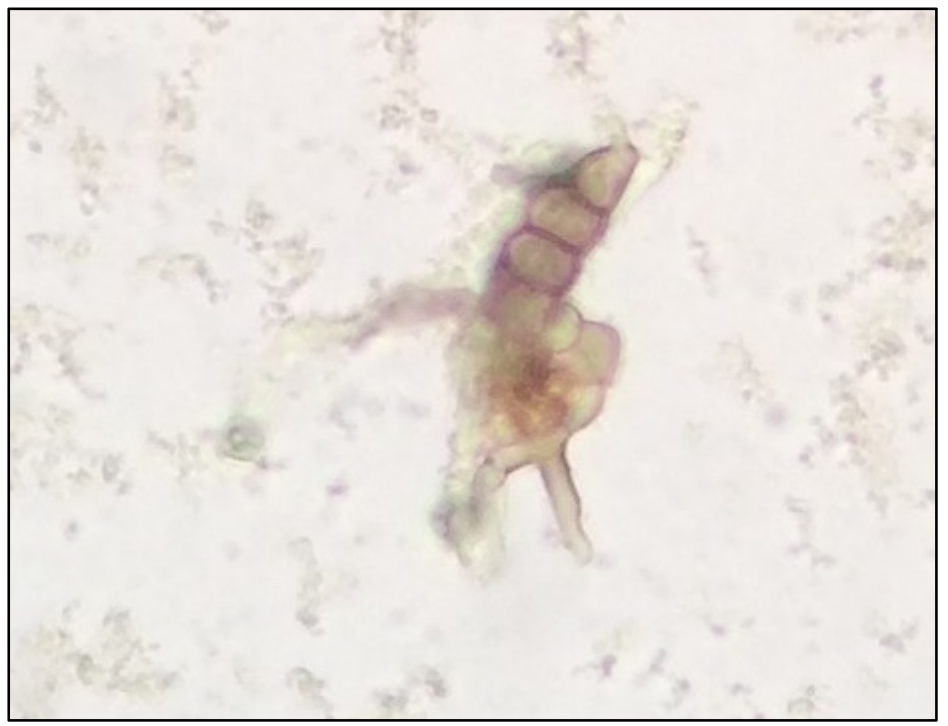

Figura 2. Imagem observada em microscopia óptica de luz (Obj. 100x). Revela a presença de hifas e conídios, obtida por raspado de pele.

A fim de confirmar o diagnóstico realizou-se a cultura fúngica dos pelos circundantes às lesões, coletados por avulsão e encaminhados para Laboratório de Análises Clínicas terceirizado, que foram cultivados em ágar Saboroud, incubados durante 7 dias, em estufa bacteriológica em temperatura 25 a $28{ }^{\circ} \mathrm{C}$. De acordo com os resultados obtidos macro e microscopicamente, a amostra foi positiva para Curvularia spp..

Para avaliação histopatológica das lesões de pele, amostras das áreas positivas no crescimento fúngico para Curvularia spp. foi obtido por meio de biópsia incisional um fragmento de pele e encaminhado para o Laboratório de Patologia e Histotécnica da Uningá, no qual realizou-se a histotécnica descrita por Hargis e Ginn (7). Tais amostras evidenciaram infiltrado de macrófagos em derme, área de necrose circundadas por infiltrado de células inflamatórias (Figura 3), caracterizando lesão crônica, característica comum em dermatites crônicas como o caso relatado.

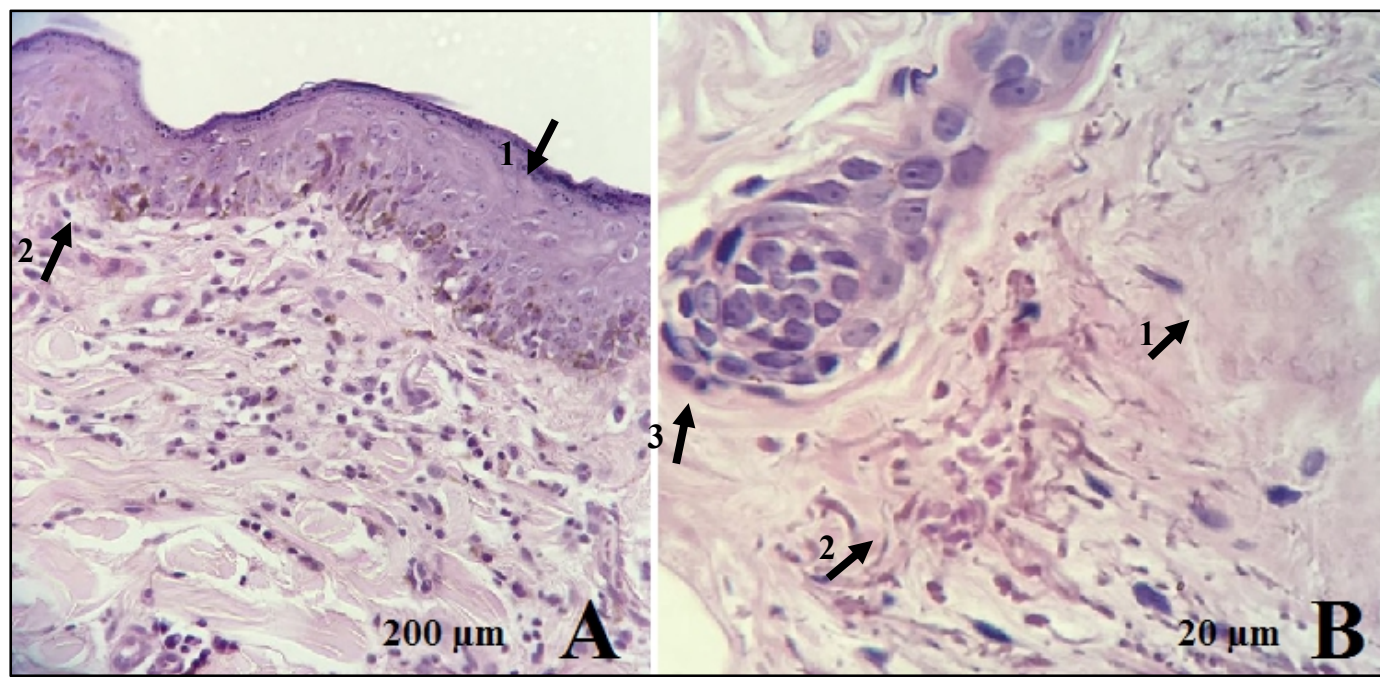

Figura 3. Setas indicam : (A) Obj. 40x: Dermatite. (Seta 1) hiperqueratose, epitélio íntegro (epiderme). (Seta 2) Infiltrado de células mononucleares em derme. (B)

Rodrigues DM, Mattosinho RO, Molinari BLD, Bezerril JE, Marcusso PF, Petrillo TR. Dermatomicose em cão causada por Curvularia sp.: Relato de caso. Vet. e Zootec. 2021;28: 001-006. 
Obj. 100x: (Seta 1) áreas de necrose circundadas por estruturas eosinofílicas amorfas (Seta 2) decorrentes do rompimento de membranas e infiltrado linfoplasmocíticohistiocitário (Seta 3).

Após o diagnóstico definitivo foi prescrito o tratamento baseado em banhos semanais com shampoo a base de clorexidine a $4 \%$, miconazol $2 \%$, com fatores hidratantes, itraconazol oral na dose de $7 \mathrm{mg} / \mathrm{kg}$ duas vezes ao dia (BID), durante 30 dias, ranitidina na dose de $2 \mathrm{mg} / \mathrm{kg}$ duas vezes ao dia (BID), durante 30 dias, como protetor gástrico. Com intuito de manter o paciente em estabilidade, foi indicado mudança na alimentação, e utilização de ômega 3,500mg uma vez ao dia (SID), até novas recomendações. Decorridos 30 dias de tratatamento, paciente apresentou resposta clínica significativa, tratamento manteve-se por mais 20 dias. Após a alta médica, paciente teve como prescrição médica continuar a administrar o ômega 3,500mg (SID) de forma ininterupta.

Clinicamente é possível identificar a presença de lesões sugestivas de afecções fúngicas dermatológicas, caracterizadas principalmente por alopecia circular, eritema e descamação. Com a expansão da dermatomicose e infecção, a subsequente coalescência das lesões dermatofíticas levam a formação de áreas alopécicas policíclicas, podendo ter infecção bacteriana secundária e prurido variável, tornando a pele hiperêmica e sensível aos estímulos termotáteis (8), assim como observado após o exame clínico e físico realizado no caso apresentado.

Autores relatam que a relação da predisposição racial em cães, acometidos por afecções fúngicas pode estar relacionada a diferenças qualitativas e/ou quantitativas na defesa cutânea, devido a produção sebácea diferentes ou por características individuais assim como o pelame do animal $(5,9)$.

Alguns exames complementares como, o exame direto do espécime clínico, através da microscopia óptica (40x), após a clarificação em solução de hidróxido de potássio - KOH (6), permite, em alguns casos, a visualização de estruturas fúngicas livres ou aderidas aos pêlos tonsurados, tais como hifas e artroconídios. A cultura fúngica é reconhecida como o método mais confiável e padrão-ouro para o diagnóstico das dermatomicoses, utilizando meios de cultura seletivos ou básicos como ágar Saboroud e ágar Mycosel (6).

O tratamento para dermatomicose envolve uso sistêmico e tópico, com itraconazol e shampoo com associação de miconazol, respectivamente. Assim como ácidos graxos são utilizados na manutenção do controle imunológico e patologias de pele (10).

\section{CONCLUSÃO}

Em casos de dermatopatias crônicas com lesões sugestivas de infecções fúngicas, o exame direto de raspado, bem como a cultura fúngica são essenciais para o diagnóstico e tratamento adequado do paciente.

\section{REFERÊNCIAS}

1. Poutahidis T, Angelopoulou K, Karamanavi E, Polizopoulou Z, Doulberis M, Latsari M, et al. Mycotic encephatitis and nephritis in a dog due to infection with Cladosporium cladosporioides. J Comp Pathol [Internet]. 2009 [cited 2016 Mar 2];140:59-63. Available from: http://www.sciencedirect.com/science/article/ pii/S0021997508001102

2. Basso PC, Raiser AG, Schmidt C, Brun MV, Souza TM, Trindade AB, et al. Dermatomicose e ceratite micótica causada por Exophiala sp. em um cão. Cienc Rural 
[Internet]. 2008 [cited 2016 Mar 2];38(7):2063-7. Available from: http://www.scielo.br/ scielo.php?script $=$ sci_arttext\&pid=S010384782008000700044

3. Antoniassi NAB, Corrêa AMR, Becker C, Sanches EMC, Ferreiro L, Driemeier D. Feohifomicose cutânea causada por Curvularia sp. em um equino. Acta Sci Vet. 2010;38(1):73-6.

4. Duarte WF, Dayo-Owoyemi I, Nobre FS, Pagnocca FC, Chaud LCS, Pessoa A, et al. Taxonomic assessment and enzymes production by yeasts isolated from marine and terrestrial Antarctic samples. Extremophiles. 2013;17(6):1023-35.

5. Brilhante RSN, Cavalcante CSP, Soares-Junior FA, Cordeiro RA, Sidrim JJC, Rocha MFG. High rate of Microporum canis feline and canine dermatophytoses in Northeast Brazil: epidemiological and diagnostic features. Mycopathologia. 2003;156(4):303-8.

6. Sidrim JJC, Rocha MFG. Micologia médica à luz de autores contemporâneos. Rio de Janeiro: Guanaba Koogan; 2004. p.135-61.

7. Hargis AM, Ginn PE. O tegumento. In: McGavin MD, Zachary JF. Bases da patologia em veterinária. 5a ed. Rio de Janeiro: Elsevier; 2013. Cap.17, p.915-1012.

8. Moriello KA. Diagnostic techniques for dermatophytes. Clin Tech Small Anim Pract. 2001;16(4):219-24.

9. Mancianti F, Nardoni S, Corazza M, D'Achille P, Ponticelli C. Environmental detection of Microsporum canis arthrospores in the households of infected cats and dogs. J Feline Med Surg. 2003;5(6):323-8.

10. Duarte AC. Nutrição imunomoduladora. In: Duarte AC. Semiologia imunológica nutricional. Rio de Janeiro: Axcel Books; 2003. p.38-144.

Recebido em: 04/11/2020

Aceito em: 28/02/2021 